\title{
Phoniatric, Audiological, Orodental and Speech Problems in a Boy with Cardio-Facio-Cutaneous Syndrome Type 3 (CFC 3) Due to a Pathogenic Variant in MAP2KI - Case Study
}

\author{
Bożena Kosztyła-Hojna' \\ Jan Borys ${ }^{2}$ \\ Maciej Zdrojkowski' \\ Emilia Duchnowska (D' \\ Anna Kraszewska (D) \\ Daria Wasilewska ${ }^{3}$ \\ Christiane Zweier ${ }^{4,5}$ \\ Alina Teresa Midro ${ }^{3}$ \\ 'Department of Clinical Phonoaudiology \\ and Speech Therapy, Medical University of \\ Białystok, Białystok, Poland; '²Department \\ of Maxillofacial and Plastic Surgery, Medical \\ University of Białystok, Białystok, Poland; \\ ${ }^{3}$ Department of Clinical Genetics, Medical \\ University of Białystok, Białystok, Poland; \\ ${ }^{4}$ Institute of Human Genetics, Friedrich- \\ Alexander-Universität Erlangen-Nürnberg \\ (FAU), Erlangen, Germany; ${ }^{5}$ Department of \\ Human Genetics, Inselspital, University \\ Hospital Bern, University of Bern, Bern, \\ Switzerland
}

\begin{abstract}
Cardio-facio-cutaneous syndrome 3 (CFC3) due to variants in $M A P 2 K 1$ is a rare genetic disorder manifested mainly by short stature, facial dysmorphism, abnormalities of the cardiovascular system, skin changes, and intellectual disability. The aim of the study is the evaluation of the occurrence of pathological changes in the upper respiratory tract, orthodontic disorders, as well as voice, speech and hearing abnormalities in an 11-year-old boy with CFC3 syndrome. The lack of detailed diagnostics of speech, voice and hearing disorders, as well as the degree of their severity was an inspiration to undertake research in this field. Pathological changes in face, oral cavity, upper respiratory tract (nose, nasopharynx, larynx), and hearing organ, as well as voice and speech quality, were assessed in an 11-year-old boy with CFC3 syndrome. Pathologies of the upper respiratory tract (adenoid hypertrophy, narrowing of the nasal passages) and laryngeal asymmetry were found without significant changes in voice quality in the acoustic examination, except for the voice timbre change confirmed in narrowband spectrography. Complex audiological assessment confirmed the existence of bilateral sensorineural hearing loss. Speech pathology assessment revealed abnormalities in the structure of articulation organ, its decreased motor efficiency, imprecision, reduced coordination, as well as the presence of autistic features. Exome sequencing showed the heterozygous variant c.371C $>$ T (p.Pro124Leu) in the MAP2K1 gene, previously described as pathogenic, thus supporting a causative relevance. Phoniatric, audiological, orodental and speech problems should be considered as features of cardio-facio-cutaneous syndrome type 3 (CFC 3) phenotype due to a pathogenic variant in MAP2K1.
\end{abstract}

Keywords: cardio-facio-cutaneous syndrome, hearing loss, voice disorders, articulation, $M A P 2 K 1$

\section{Introduction}

Cardio-Facio-Cutaneous syndrome 3 (CFC3) (OMIM \# 615279) is a rare genetic condition caused by heterozygous variants in the MAP2K1 (MEK1) (OMIM * 176872) gene located on chromosome 15 at locus q22, mainly in exons 2 and 3 . $^{1}$ CFC syndrome belongs to the RASopathies - a group of syndromes with overlapping clinical features resulting from a common pathogenetic mechanism. Pathogenic variants of one of the at least four different genes belonging to the $R A S / M A P K$ signaling pathway, namely BRAF (OMIM 164757), KRAS (OMIM 190070), MEK1 (MAP2K1) (OMIM 176872) or MEK2 (OMIM 601263) are
Correspondence: Emilia Duchnowska Department of Clinical Phonoaudiology and Speech Therapy, Medical University of Białystok, ul. Szpitalna 37, Białystok, 15-295, Poland

Tel +48603330294

Email emilia.duchnowska@umb.edu.pl 
responsible for disorders in CFC syndrome. Accordingly, four types of CFC syndrome are described, CFC1 (OMIM\#115150), CFC2 (OMIM\#615278), CFC3 (OMIM\#615279), and CFC4 (OMIM\#615280). ${ }^{2-4}$ Overlapping phenotypic traits are recorded in other rasopathies, such as Noonan and Costello syndromes. ${ }^{5,6}$

The name CFC derives from the first description of repeating phenotype features in a group of eight subjects by American geneticists in $1986 .^{7}$ Cardiological changes (including congenital heart defects), characteristic facial dysmorphism and skin changes were observed, providing the basis for the name of this syndrome. Short stature was also described, as well as characteristic features of the face including high forehead, bilateral constriction of the temporal area, underdevelopment of the supraorbital arches, narrowing of the palpebral fissures, collapse of the nasal bridge, and backwards rotation of the low-positioned large auricles. ${ }^{7}$ Hair was reported as sparse, curly, and brittle. Skin lesions were classified as hyperkeratosis and ichthyosis. $^{8}$

The presence of abnormalities in the structure of the hearing organ, laryngotracheomalacia, voice disorders and various degrees of delay in the development of speech are noticeable. ${ }^{9-11}$ These changes may be considered as distinctive features of CFC3 syndrome. The lack of detailed diagnostics of speech, voice and hearing disorders, as well as the degree of their severity was an inspiration to undertake research in this field.

The aim of the study was to assess the occurrence of pathological changes in face, upper respiratory tract, hearing organ, oral cavity, voice and speech quality disorders in an 11-year-old boy diagnosed with CFC3 syndrome due to a pathogenic variant of the $M A P 2 K 1$ gene.

\section{Materials and Methods}

The boy was referred to the genetic unit because of short stature, macrocephaly, facial dysmorphism and developmental delay. At the age of 10, exome sequencing on an Illumina HiSeq 2500 after enrichment with, and filtering for variants of 1290 genes associated with neurodevelopmental disorders (SysID database, status December 2019) was performed. ${ }^{12}$ Segregation testing in the parents as well as in the cousin who presented similar phenotypes: short stature, neurodevelopmental delay and autism, was performed by Sanger sequencing. Sample identities were confirmed with microsatellite markers.

Due to the presence of voice, hearing and speech abnormalities, the boy was referred to the Department of
Clinical Phonoaudiology and Speech Therapy of Medical University of Bialystok.

Orthodontic evaluation was performed at the Department of Maxillofacial and Plastic Surgery, Medical University of Białystok including craniofacial structure, occlusal condition and dental disorders.

The nose was visually assessed - anterior rhinoscopy as well as endoscopy of the nasal passages and nasopharynx were performed with the use of a flexible Xion fiberscope. The size of the nasal conchae, their color, patency of the nasal passages, the posterior nostrils and the nasopharyngeal roof were also examined.

The voice organ was assessed with videoendoscopy of the larynx using EndoSTROB EL f. Xion with rigid endoscope with an integrated microphone and $70^{\circ}$ optics of the same producer. The mobility of vocal folds during breathing and phonation, the mobility of the arytenoids, the condition of the mucosa and the symmetry of vocal canal were examined.

Acoustic evaluation of voice was conducted during the two-fold phonation of the vowel "a" spoken in isolation and the continuous, phonematically balanced linguistic text,: "Dziś jest ładna pogoda ..." ("Today is nice weather ..." "). The value of Maximum Phonation Time (MPT) was assessed. Acoustic examination included the analysis of Fundamental Frequency (F0) as well as Jitter (frequency variation from cycle to cycle), Shimmer (amplitude variation of the sound wave) and NHR (Noise-to-Harmonics Ratio) values. In the acoustic examination, "Diagnoscope Specjalista" software by Diagnova Technologies was used. Narrowband spectrography was performed analyzing harmonic and non-harmonic components within the whole frequency range. The examination was conducted in a soundproofed room with using SHURE SM86 microphone with a cardioid characteristics and an extended upper band.

The auricles were assessed visually and a speculum assessment of the external auditory canals and the tympanic membranes was also performed. Conductive or sensorineural hearing loss type was assessed using Rinne and Weber tests. ${ }^{13}$ Hearing was assessed acumetrically from a distance of $6 \mathrm{~m}$ and audiometrically with the use of the Interacoustics AA222 audiometer in an acoustically soundproofed room. The level of the threshold curve for air and bone conduction was assessed by analyzing the size of the cochlear reserve. Distortion product otoacoustic emission (DPOAE) was performed using Madsen Capella ${ }^{2}$ by Otometrics. Tympanometric examination was 
conducted using Madsen Otoflex 100 by the same producer. Obtained result was classified as type A, B, C, $\mathrm{A}_{\mathrm{s}}$ or $A_{d}$, where type $A$ is normal acoustic impedance, type B confirms the presence of fluid in middle ear, type $\mathrm{C}$ indicated the dysfunction of Eustachian tube, type $\mathrm{A}_{\mathrm{s}}$ indicated the immobilization of auditory ossicles, type $A_{d}$ discontinuity of ossicles chain. Examination was conducted in soundproofed room meeting the norms for acoustic measures.

The motor function of the articulation organ was examined using a questionnaire based on Kurkowski and Woźniak ${ }^{14}$ evaluating the efficiency of the tongue, lips, mandible and soft palate. The result was given in points. The Logopedic Test for Children and Young Adults (Logopedyczny Test dla Dzieci i Młodzieży Michalak-Widera) was used to examine the articulation. ${ }^{15}$ Auditory perception - phonemic hearing, which is the ability to auditory differentiate distinctive features of phonemes (in speech - differentiation of sound from sound), was examined using tables with paronyms (words which sound similar but have different meaning) prepared by Styczek. ${ }^{16}$ The level of auditory analysis and synthesis was examined with the Styczek test including differentiating sounds in word heard and creating a word from syllables and sounds heard. ${ }^{16}$ Auditory phonological memory was assessed by repeating senseless words different in terms of phonetic complexity; own tests were used. The assessment of linguistic and communication competence was conducted on the basis of analysis of spontaneous speech, understanding questions and commands, understanding and naming parts of speech, dialogue skills and telling picture stories.

The assessment of the intensity of presented autistic symptoms was conducted with the application of Autism Quotient (AQ) for children according to Auyeung et $\mathrm{al}^{17}$ in the Polish version according to Pisula, Rynkiewicz and Łucka. ${ }^{17}$ AQ questionnaire contains 50 questions regarding psychosocial aspects of human functioning including communication, imagination, the ability to focus and redirect attention, social skills and attention to details. ${ }^{17}$ The structure of questions allows to give equal number of positive and negative answers. Answers are given in 4-point Likert scale: "strongly agree", "rather agree", "rather disagree", "strongly disagree". This is a "forcedchoice scale". For every answer, 0, 1, 2 or 3 points may be given. The maximum score is 150 , lower scores indicate lesser intensity of autistic features. ${ }^{17}$
The Childhood Autism Spectrum Test (CAST) was performed according to Scott et $\mathrm{al}^{18}$ also in a Polish version according to E. Pisula and A. Rynkiewicz. ${ }^{18}$ The test contains 37 questions with positive or negative answer. The maximum score is 31 . Higher results indicate higher intensity of autistic features. ${ }^{18}$

\section{Results}

The boy was born at gestational week 38 after an uneventful pregnancy. After birth, the boy received 10 points on the Apgar scale. Cooing appeared at 3 months of age, babbling at 6 months, and first words after 1 year of age. After this period, the occurrence of echolalia and a significant delay in speech development were observed.

Due to his short stature and weight deficiency, he was treated with growth hormone from the age of 5 years with successful results. He underwent smallpox and frequent infections of the upper respiratory tract. Furthermore, heart murmurs without a cardiac malformation as well as skin changes like keratosis pilaris, livedo, a Cafè-au-lait spot and some nevi were observed.

The behavior of the boy was suggestive of an autistic disorder. He had selective skills and interests in logical games as well as difficulties to establish contact with his peers, he was physically active. From the age of 3, he was under early development support program and from the age of 5 - under a special education program. Currently, he is in the 4th integrated class for autistic children and receives pedagogic therapy, speech therapy and physiotherapy with swimming exercises.

Exome sequencing was performed at age of 10 which revealed the variant c. $371 \mathrm{C}>\mathrm{T}$ (p.Pro124Leu) in $M A P 2 K 1$ (NM_002755.3), which was shown to occur de novo and was additionally excluded in the similarly affected cousin. This variant has been reported previously as pathogenic (ClinVar accession VCV000040744.1). Therefore, CFC3 syndrome was diagnosed in the boy.

Assessment of the morphological phenotype (Figure 1A-C) revealed asymmetric small face, shorter and flattened on the left side with bilateral constriction of the temporal area, high forehead, underdeveloped supraorbital arches and wide palpebral fissures. The malar prominences and lower orbital rims were bilaterally reduced. The auricles were large and low set, slightly rotated backwards in the upper part (Figure 1A-C). The left auricle was protruded, low-set and rotated backwards (Figure 1B and C). Irregularly shaped hyperpigmented area on the right forehead was visible (Figure 1A and B). Multiple 


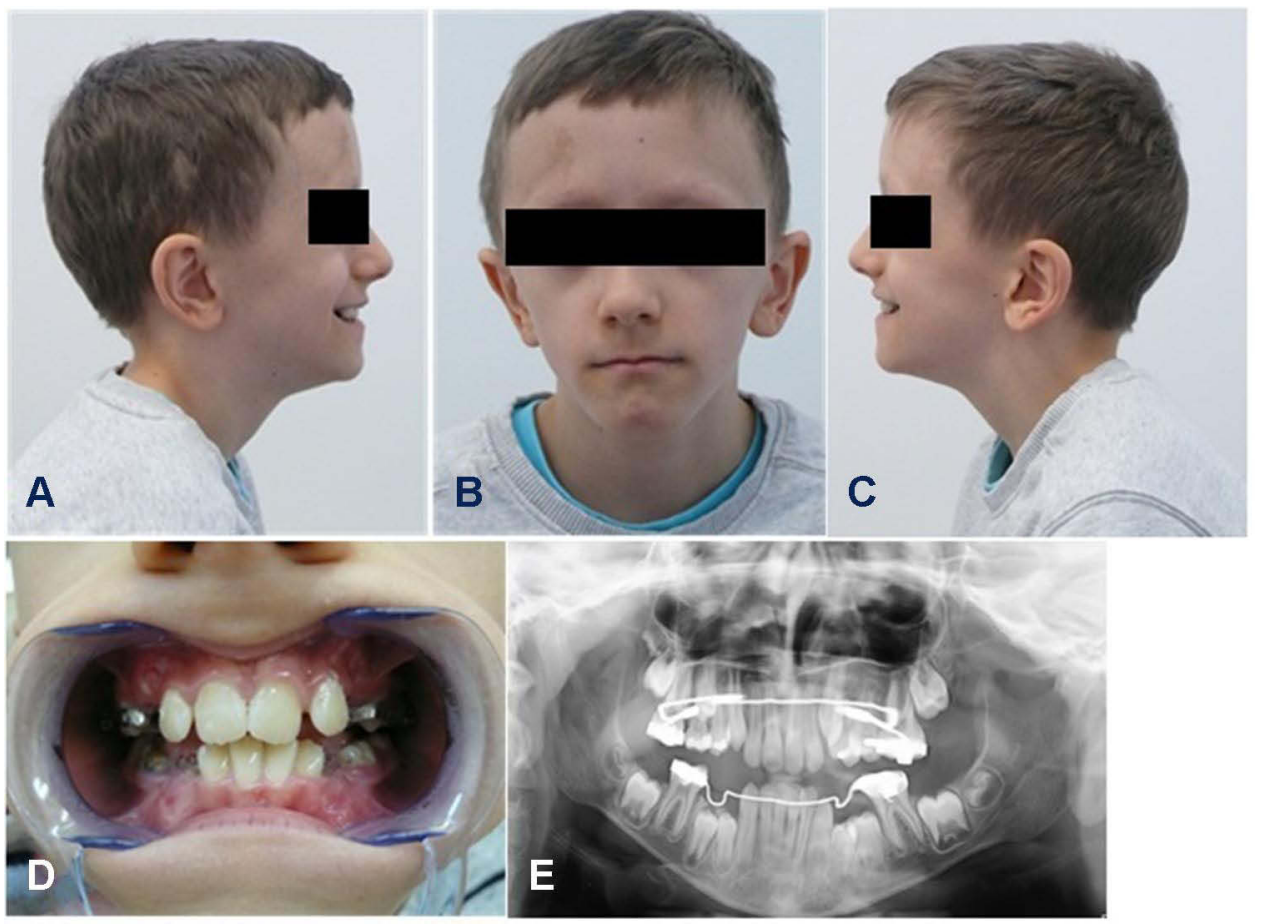

Figure I Facial phenotype (A-C), occlusion (D) and panoramic radiograph (E).

melanocytic nevi with a diameter of approximately 1$2 \mathrm{~mm}$ were located on the forehead (one) and the preauricular area (one), on the left side of the face, on the skin of the lower eyelid (one), the cheek (one) and neck (three) on the right side (Figure 1B and C). Symmetrical nose was short; the nasal passages were narrow; the nasal conchae were of the correct size and the nasal patency was limited on both sides (Figure 1A-C). Endoscopically, in the area of the nasopharynx, hypertrophy of the pharyngeal tonsil occupying the top of the nasolacrimal and reaching the posterior nostrils was found, which resulted in their partial blockage (Figure 2). The chin was small and mildly asymmetric (Figure 1B). The position of the mouth slit was oblique - the left corner of the mouth was located slightly higher in relation to the right side. The lips were thin and hypotonic with a narrow vermilion border of the upper lip. The patient was breathing through his mouth and when he closed his mouth, there was a visible hypertonia of the mentalis muscle. The lower part of the face was slightly elongated and the facial profile appeared mildly convex (Figure 1A-C).

In intraoral examination, the hard palate was narrow, highly arched, while the soft palate was long, continuous, slightly tense, with preserved mobility. Mixed dentition in the oral cavity was noticed, with visible deciduous molars in the maxilla, erupted permanent upper and lower incisors,

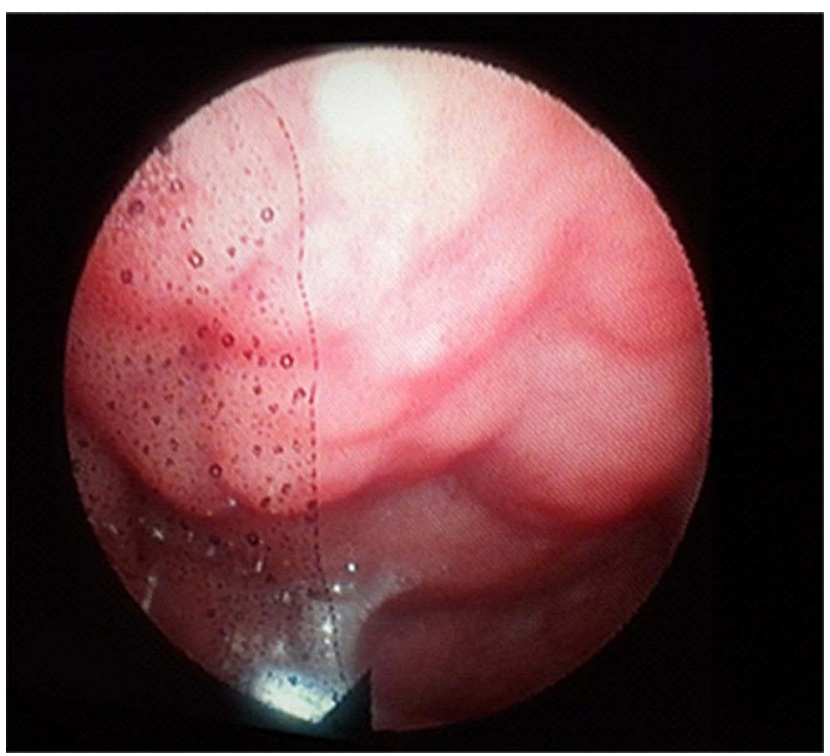

Figure 2 Hypertrophy of the pharyngeal tonsil registered using a flexible endoscope and EndoSTROB EL videostroboscope f. Xion.

canines and permanent first molars in the maxilla and mandible. Lower incisors were crowded. Dental caries and permanent filling in deciduous and permanent molars were found. The occlusal plane was slightly oblique in relation to the pupil line according to the rules of orthodontic examination. The midline of the lower dental arch was shifted to the left by $3 \mathrm{~mm}$ in relation to the midline of the upper dental arch. The patient 

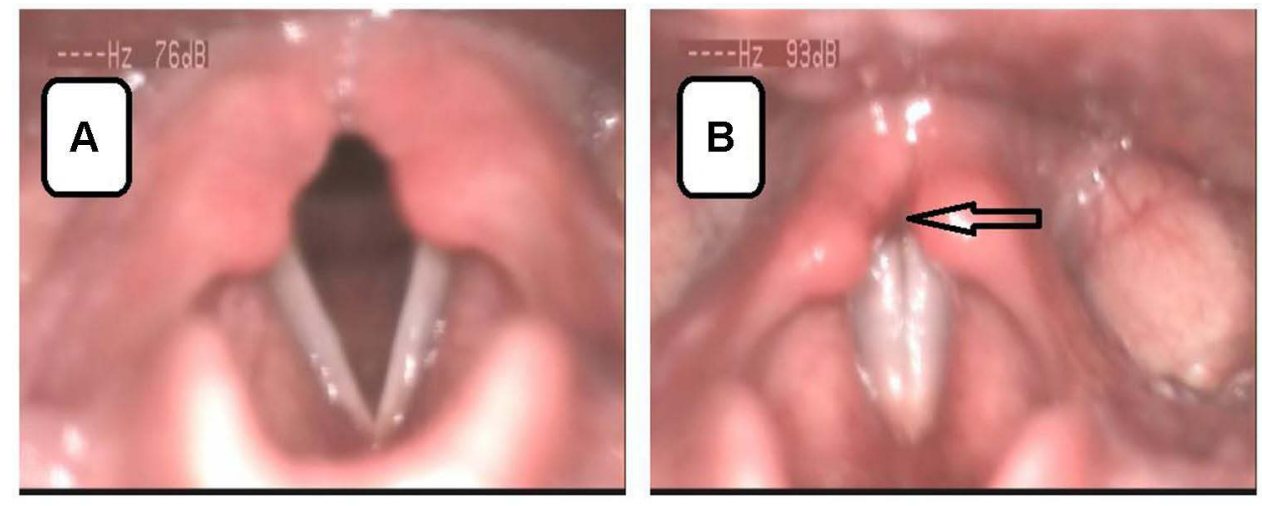

Figure 3 Asymmetry of arytenoid cartilages with edema and redness of intraarytenoid area; (A) respiratory position of vocal folds, (B) phonatory position of vocal folds.

was wearing orthodontic braces due to narrowing of the upper and lower dental arch and bilateral cross bite (Figure 1D and $\mathrm{E}$ ).

Endoscopic examination revealed free laryngeal entrance, tubular epiglottis in retroflexion, slightly atrophic vocal folds stuck with thick mucus. During phonation, glottal insufficiency was found at the physiological limit as well as asymmetry of both arytenoids with edema and congestion of the mucosa, especially in the intraarytenoid area. The mucosa was excessively dry and covered with thick secretion (Figure 3).

Maximum Phonation Time (MPT) in the acoustic assessment was on average 6.8 seconds. The Fundamental Frequency - F0 reached an average value of $232 \mathrm{~Hz}$. The values of Jitter, Shimmer, Noise-toHarmonics Ratio (NHR) were normative. In narrowband spectrography, harmonics in the low-frequency range and a few non-harmonic components in the medium and high frequencies were recorded (Figure 4).

With the speculum examination, ear canals were narrow with a small amount of cerumen. The tympanic membranes were silver-white with slightly diminished light reflection and showed no signs of perforation. The Weber test result was referred to as "Central Weber"; Rinne tests as "Rinne positive". In Rinne test, air conduction was longer and stronger than bone conduction. Whispering was recorded from a distance of 6 meters for RE and LE in accumetry. Audiometry showed a bilateral sensorineural hearing loss of $10 \mathrm{~dB}$. In DPOAE, normal values of acoustic impedance within the range of 1 to $6 \mathrm{kHz}$, except the frequency of $8 \mathrm{kHz}$ where values of $-10 \mathrm{~dB}$ for $\mathrm{RE}$ and $-3 \mathrm{~dB}$ for $\mathrm{LE}$ were obtained. In tympanometry normal tympanometric curves were recorded classified as type A for RE and LE, respectively, $0.38 \mathrm{~mL}$ and $0.67 \mathrm{~mL}$ (Figure 5).
In logopedic assessment, the boy obtained 13 out of 18 points in the general evaluation of the motor function of the articulatory organ. There were no anomalies in the structure of the tongue or the tongue frenulum. Slight decrease in the muscle tone of the tongue and the lack of precision of the movements performed were observed. During some of the tests, the boy used auxiliary movements of the lower and upper lip as well as the mandible. In assessing the efficiency of the lips, the boy received 9 out of 11 points. The boy did not perform the task of alternately extending and stretching the lips and the task of whistling. In anatomical structure of lips, flat upper lip with narrow vermilion border was observed. During the examination, slight hypotonia and efficiency of muscles responsible for lips movement were visible. The boy needed to put an effort to perform the tests. Tests for the efficiency of the mandible and soft palate were executed correctly; the boy obtained 4 of 4 points in the assessment of the mandibular efficiency; in the assessment of the activity of the soft palate, he obtained 2 of 2 points. In the overall assessment of the motor activity of the articulation organs, the child received 28 out of 35 points, which proves a reduction in the motor skills of organs, especially the tongue. Breathing pattern (costodiaphragmatic), respiratory-phonation coordination and swallowing pattern did not show abnormalities. The assessment of articulation revealed rhotacism - hyper-correct articulation of the sound $[\mathrm{r}]$ in all vocal positions and phonetic combinations. In terms of perception, no disorders of phonemic hearing were found, and no disturbances in the auditory analysis and synthesis or auditory phonological memory were observed. In terms of linguistic competence in spontaneous speech, the boy most often used single sentences, generally correct in terms of 

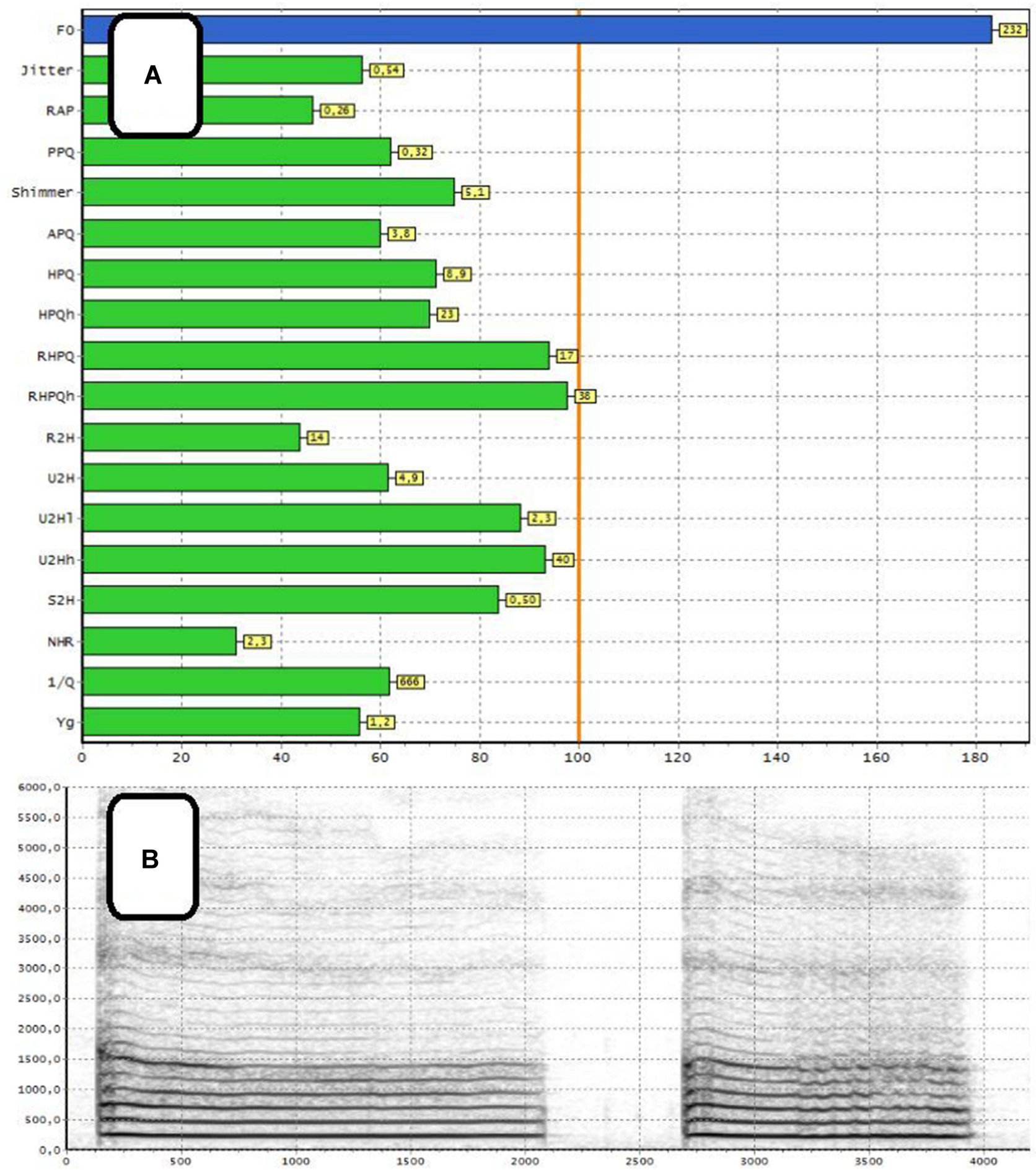

Figure 4 Voice acoustic analysis using Diagnoscope Specjalista by Diagnova Technologies; (A) collective analysis of acoustic parameters, (B) narrowband spectrography.

grammatical structure and syntax. Direct and delayed echolalia occurred sporadically. He participated in the dialogue and generally kept alternating statements. In the narrative speech, he used simple expressions and sentences, usually grammatically and syntactically correct.
The narrative line and the cause-effect sequence were preserved, and consistency of the statement was reduced. In terms of communicative competence, linguistic social, situational and pragmatic efficiency was reduced in relation to age. 


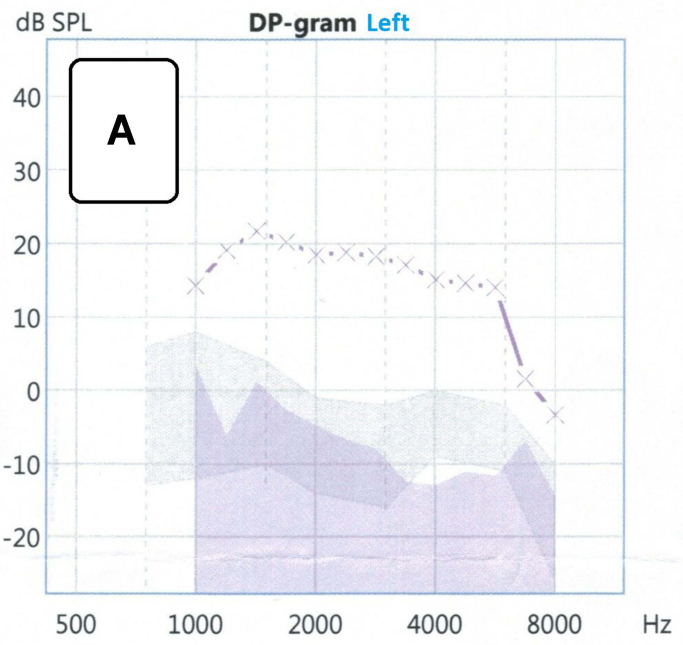

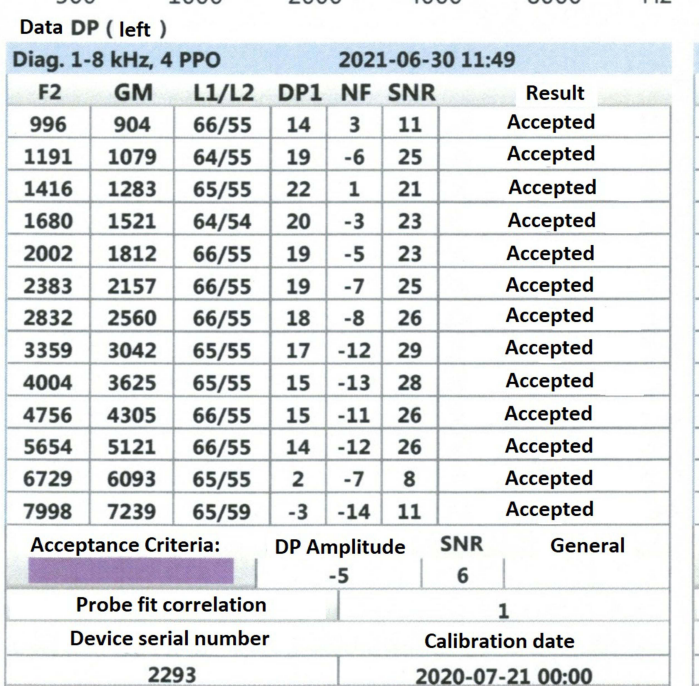

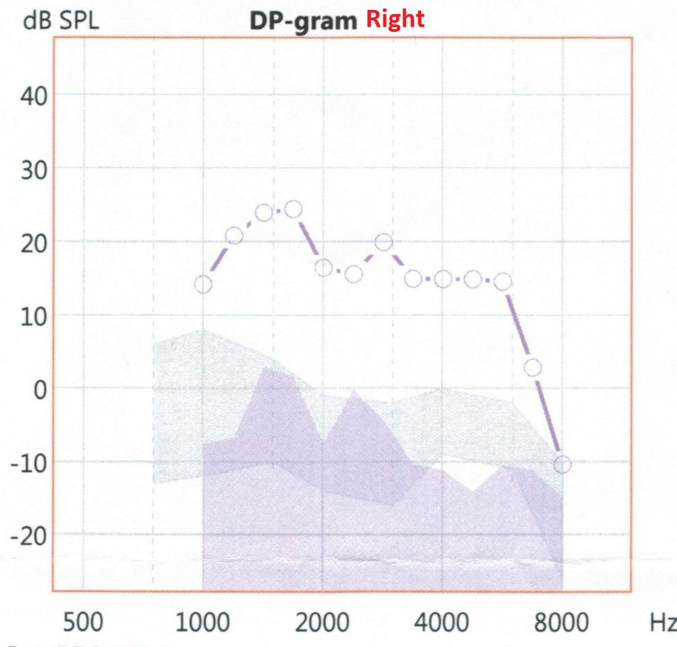

Data DP ( right )

Diag. 1-8 kHz, 4 PPO 2021-06-30 11:47

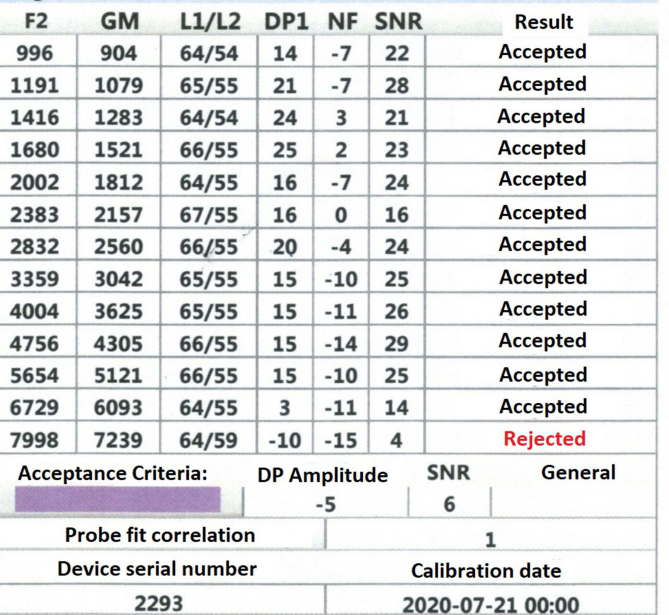
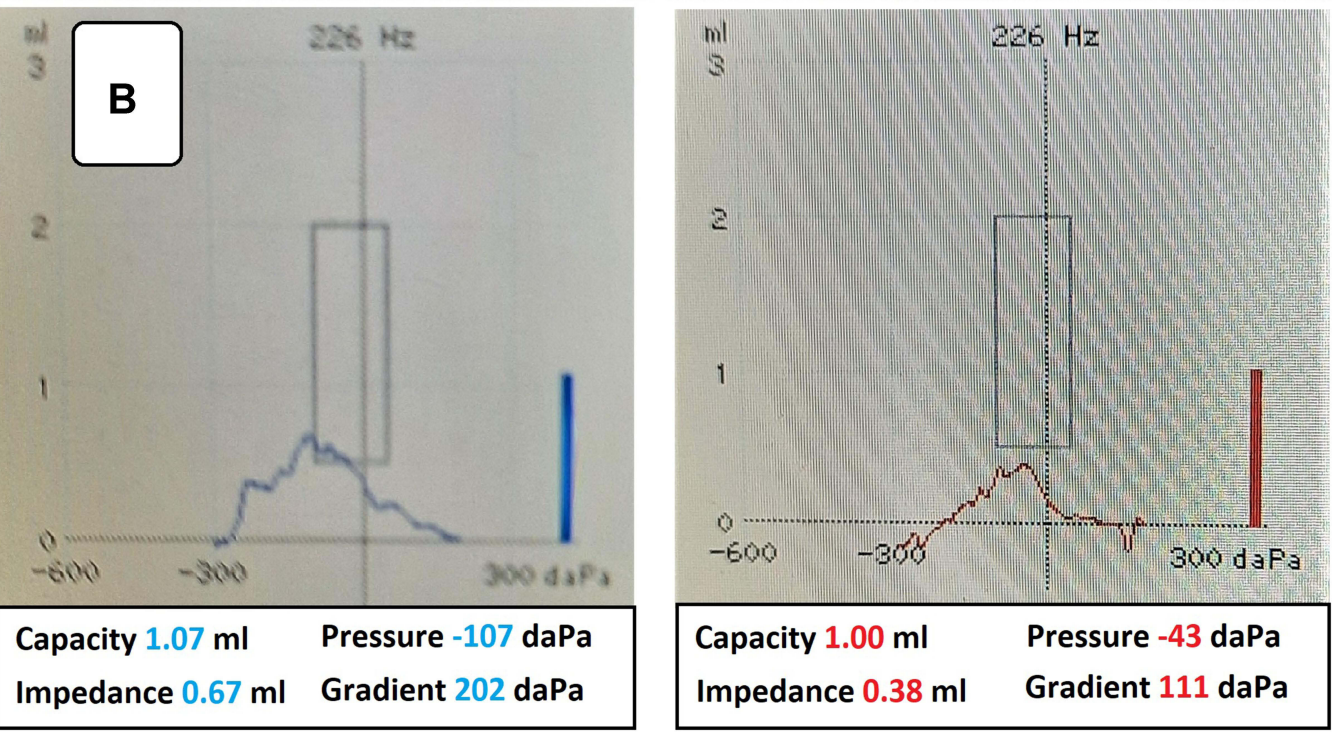

Figure 5 Bilateral sensorineural hearing loss. (A) DP-grams registered with Madsen Capella ${ }^{2}$; (B) tympanograms registered with Madsen Otoflex I00 by Otometrics. 
In the assessment of the intensity of autistic features with the AQ questionnaire, the boy obtained 78 points, which indicates various problems in the field of social functioning, communication and imagination. He had difficulty making friends, was isolated, could not follow a conversation of several people, read non-literal content, he was more interested in things than other people, and he concentrated on small elements and side plots. New situations disturbed him, routine in performing activities was important to him. He tended to concentrate on one activity and was interested in numbers.

The boy obtained 10 points in the CAST examination. It was not important for him to belong to a peer group, he noticed details that others did not pay attention to. He had difficulty interacting with other children. He displayed an extraordinary memory for detail. He often directed the conversation to his favorite topic instead of following the interlocutor, etc. The greatest difficulties were recorded in the boy's social aspect of functioning. The above behaviors prove the specificity of interests and skills, which is characteristic for children with autism.

\section{Discussion}

Cardio-Facio-Cutaneous Syndrome (CFC) should be suspected in individuals with characteristic phenotypic features related to the heart, face and ectodermal structures [10]. Also larynx, hearing, vision, gastrointestinal tract (Gastroesophageal Reflux Disease - GERD) as well as the skeletal and endocrine systems (short stature) might be affected. ${ }^{5,19}$ The diagnosis of the syndrome is based on the presence of phenotypic features according to the diagnostic index score by Kavamura et al. ${ }^{6}$ Confirmation of the clinical diagnosis is possible thanks to molecular tests. ${ }^{6,20}$

The phenotype may be ambiguous; however, short stature, neurodevelopmental delay, typical for CFC syndrome were confirmed by unbiased, objective genetic testing.

In the herewith reported boy, abnormalities of the ears and auditory system included sensorineural hearing loss of $10 \mathrm{~dB}$, low-set and mildly rotated auricles and narrow external auditory canals. Similar structure of the auricles and sensorineural hearing loss were recorded by Pierpont et $\mathrm{al}^{9}$ in CFC syndrome who simultaneously recommended systematical audiological control in these children. According to Rauen, ${ }^{11}$ children with CFC syndrome may also suffer from recurrent otitis media, which is an indication of frequent ENT controls. According to Pierpont et $\mathrm{al}^{9}$ no systematic evaluation has yet been done to determine the prevalence or type of hearing loss in children with CFC syndrome. The sensorineural, conductive and mixed hearing impairment up to the age of 3 may have adverse effects on the development of the child's voice and speech according to De Schrijver et al. ${ }^{21}$ Hearing impairment occurs in many genetically determined syndromes. Sensorineural hearing loss is common in Turner, Richieri, Costa Pereira, Pendred and NSEVA syndromes. ${ }^{22-26}$

Narrow nasal passages and adenoid overgrowth restricted the nasal obstruction, forcing the patient to breathe through an open mouth. Pathological breathing pathway through the open mouth may cause orthodontic disorders and malocclusions, and exacerbate the features of dry upper respiratory and laryngeal mucosa congestion. ${ }^{6,27-29}$ In the examined boy, a tendency to breathe through the mouth, distal occlusion and other orthodontic disorders causing the need of orthodontic braces application. ${ }^{10,19-21}$

Endoscopic examination of the larynx revealed dry congestion of the upper respiratory tract and larynx mucosa with the presence of thick secretions as well as arytenoid cartilages asymmetry and edema. Also redness of intraarytenoid area mucosa suggesting the coexistence of Gastroesophageal Reflux Disease (GERD) which next to osteoarticular and endocrinological system pathologies was registered which was documented also by Rauen. ${ }^{11}$ Arytenoid cartilages asymmetry in diagnosed boy indicates the existence of larynx anomalies, which were also registered by Miguel et $\mathrm{al}^{26}$ in patients with autosomalrecessive syndrome Richieri Costa Pereira. Next to larynx anomalies in patients with this syndrome, the authors also described the existence of characteristic short stature, discrepancies of mandible and cleft palate. According to Bonilha et $\mathrm{al}^{30}$ asymmetry of the mobility of arytenoid cartilages may cause significant disturbances in voice quality or may proceed without symptoms of dysphonia. They showed that $70 \%$ of subjects with asymmetry of arytenoid mobility may have a physiological (euphonic) voice. In the diagnosed boy, acoustic examination revealed a significant reduction of Maximum Phonation Time (MPT); however, other parameters of acoustic voice analysis: Jitter, Shimmer and NHR were normative. This is consistent with the reports of Bonilha et $\mathrm{al}^{30}$ where the authors did not register any disturbances in voice quality with the coexisting asymmetry of arytenoids. The lack of voice quality disturbances in the diagnosed boy was confirmed by the results of narrowband spectrography, where harmonics in the low-frequency range and a few nonharmonic components in the medium and high frequencies were recorded. The presence of nonharmonic components in the range of medium and high frequencies could be 
caused by the non-physiological breathing resulting from adenoid hypertrophy and narrow nasal passages disturbing the geometry of resonating cavities.

According to Pierpont et $\mathrm{al}^{9}$ in young children with CFC syndrome, apart from hearing disorders, laryngeal and tracheal laxity, defined as laryngotracheomalacia, may occur and it requires long-term ENT care. In the examined boy, apart from tubular epiglottis, which is typical for children, its retroflexion and arytenoid asymmetry, no laryngotracheomalacia was recorded.

The overall anatomical and functional assessment of the articulation organ showed a reduction in its motor efficiency. Muscular hypotonia, including articulatory muscles, as well as speech development delay in CFC syndrome was described by Rauen. ${ }^{11}$ The existence of speech development delay and intellectual disability in children with $\mathrm{CFC}$ were also recorded by Ciara et al. ${ }^{10}$ According to Rauen ${ }^{11}$ CFC syndrome may have mild to severe cognitive impairment, although some patients may have an IQ within the normal range. According to Adviento et $\mathrm{al}^{31}$ communication disorders observed in patients with CFC, registered also in diagnosed boy, may be caused by the coexistence of autism spectrum disorders (ASD). Similar results were obtained by Garg et $\mathrm{al}^{32}$ who registered coexistence of ASD symptoms in 54\% of children with CFC syndrome. In the herewith reported boy, problems with communication were confirmed by examination with autism symptoms severity test - AQ, as well as problems with social functioning and imagination were detected. Examination with CAST additionally confirmed difficulties in social aspect of functioning. According to Adviento et $\mathrm{al},{ }^{30,31}$ an increased risk of autism spectrum disorders is related to the malfunctioning of the $R A S /$ $M A P K$ signaling pathway, which is disturbed in the examined boy by mutation of the $M A P 2 K 1$ gene. Interestingly, autism spectrum disorder has been observed in the cousin of our proband with great similarity of morphological phenotype between both, but he did not carry the $M A P 2 K 1$ variant. It is therefore possible that another, independent cause for the neurodevelopmental problems might be present in this family.

The presence of autistic disorders in CFC syndrome may be considered as a limitation during the diagnostic procedures of voice, speech and hearing disorders, especially in tests, which require cooperation of the patient. This is the reason why the diagnostics of CFC syndrome should include objective methods allowing unequivocal determination of clinical form of pathology as well as monitoring of the effects of applied treatment and rehabilitation.

\section{Conclusion}

1. In phoniatric and logopedic examinations, abnormalities in the structure of voice and speech organ pathological changes in the upper respiratory tract were stated which caused changes in voice timbre confirmed in narrowband spectrography as well as articulation and articulatory motor disorders.

2. Audiologically, using audiometry, for tunes, acoustic otoemission and tympanometry, the bilateral sensorineural hearing loss was registered.

3. Voice, speech and hearing disorders indicate the necessity of systematic, objective phoniatric-audiological and complex logopedic control in children with CFC syndrome.

4. Concomitant disorders of facial morphology, occlusal conditions and dental disorders in the described patient require constant monitoring during the growth period as well as dental, orthodontic and surgical treatment.

5. Phoniatric, audiological, orodental and speech problems should be considered as features of Cardiofacio-cutaneous syndrome type 3 (CFC 3) phenotype due to a pathogenic variant in $M A P 2 K 1$.

\section{Ethics Approval and Informed Consent}

Institutional approval was not required to publish case details. Patient's guardians had given written informed consent for the publication of case details and accompanying images.

\section{Disclosure}

The authors report no conflicts of interest in this work.

\section{References}

1. Chen J, Che $\mathrm{L}, \mathrm{Xu} \mathrm{C}$, et al. Cardio-facio-cutaneous syndrome-associated pathogenic MAP2K1 variants activate autophagy. Gene. 2020;733:144369. doi:10.1016/j.gene.2020.144369

2. Dentici ML, Sarkozy A, Pantaleoni F, et al. Spectrum of MEK1 and MEK2 gene mutations in cardio-facio-cutaneous syndrome and genotype-phenotype correlations. Eur J Hum Genet. 2009;17 (6):733-740. doi:10.1038/ejhg.2008.256

3. Nava C, Hanna N, Michot C, et al. Cardio-facio-cutaneous and Noonan syndromes due to mutations in the RAS/MAPK signaling pathway: genotype-phenotype relationships and overlap with Costello syndrome. J Med Genet. 2007;44(12):763-771. doi:10.1136/ jmg.2007.050450 
4. Emery CM, Vijayendran KG, Zipser MC, et al. MEK1 mutations confer resistance to MEK and B-RAF inhibition. Proc Natl Acad Sci U S A. 2009;106(48):20411-20416. doi:10.1073/pnas.0905833106

5. Narumi Y, Aoki Y, Niihori T, et al. Molecular and clinical characterization of cardio-facio-cutaneous (CFC) syndrome: overlapping clinical manifestations with Costello syndrome. Am J Med Genet A. 2007;143A(8):799-807. doi:10.1002/ajmg.a.31658

6. Kavamura MI, Peres CA, Alchorne MM, Brunoni D. CFC index for the diagnosis of cardiofaciocutaneous syndrome. Am J Med Genet. 2002;112(1):12-16. doi:10.1002/ajmg.10681

7. Reynolds JF, Neri G, Herrmann JP, et al. New multiple congenital anomalies/mental retardation syndrome with cardio-facio-cutaneous involvement - the CFC syndrome. Am J Med Genet. 1986;25 (3):413-427. doi:10.1002/ajmg.1320250303

8. Seth S, Biswas T, Biswas B, Roy A, Datta AK. Cardiofaciocutaneous syndrome: case report of a rare disorder. J Clin Diagn Res. 2016;10 (11):SD01-SD02.

9. Pierpont MEM, Magoulas PL, Adi S, et al. Cardio-facio-cutaneous syndrome: clinical features, diagnosis, and management guidelines. Pediatrics. 2014;134(4):e1149-e1162. doi:10.1542/peds.2013-3189

10. Ciara E, Pelc M, Jurkiewicz D, et al. Is diagnosing cardio-faciocutaneous (CFC) syndrome still a challenge? Delineation of the phenotype in 15 Polish patients with proven mutations, including novel mutations in the BRAF1 gene. Eur J Med Genet. 2015;58 (1):14-20. doi:10.1016/j.ejmg.2014.11.002

11. Rauen KA. Cardiofaciocutaneous syndrome. In: Adam MP, Ardinger HH, Pagon RA, editors. GeneReviews ${ }^{\circledR}$. Seattle: University of Washington, Seattle; 1993.

12. Kochinke K, Zweier C, Nijhof B, et al. Systematic phenomics analysis deconvolutes genes mutated in intellectual disability into biologically coherent modules. Am J Hum Genet. 2016;98(1):149-164. doi:10.1016/j.ajhg.2015.11.024

13. Kong EL, Fowler JB. Rinne test. In: StatPearls [Internet]. Treasure Island (FL): StatPearls Publishing; 2021. PMID: 28613725.

14. Kurkowski M, Woźniak T. Badanie sprawności motorycznej narządów mowy [Examination of Motor Efficiency of Speech Organs]. Zakład Logopedii i Językoznawstwa Stosowanego, UMCS Lublin. 2016.

15. Michalak-Widera I. Logopedyczny Test dla Dzieci i Młodzieży [Logopedic Test for Children and Young Adults]. Katowice: Wydawca Unikat 2; 2009.

16. Styczek I. Badanie i kształtowanie słuchu fonematycznego [Testing and Shaping Phonemic Hearing]. Warszawa: Wydawnictwo Szkolne i Pedagogiczne; 1982.

17. Auyeung B, Baron-Cohen S, Wheelwright S, Allison C. The Autismspectrum quotient: children's version (aq-child), autism research centre, University of Cambridge, UK. J Autism Dev Disord. 2008;38(7):1230-1240. (Polish version: Pisula E, Rynkiewicz A, Łucka I. 2010). doi:10.1007/s10803-007-0504-z

18. Scott F, Baron-Cohen Bolton P, Brayne C, Brayne C. CAST autism research centre, University of Cambridge, UK. Autism. 2002;6 (1):9-31. (Polish version: Pisula E, Rynkiewicz A. 2012). doi: $10.1177 / 1362361302006001003$

The Application of Clinical Genetics

\section{Publish your work in this journal}

The Application of Clinical Genetics is an international, peerreviewed open access journal that welcomes laboratory and clinical findings in the field of human genetics. Specific topics include: Population genetics; Functional genetics; Natural history of genetic disease; Management of genetic disease; Mechanisms of genetic disease;
19. Goodwin AF, Oberoi S, Landan M, et al. Craniofacial and dental development in Costello syndrome. Am J Med Genet A. 2014;164A (6):1425-1430. doi:10.1002/ajmg.a.36475

20. Gripp KW, Lin AE, Nicholson L, et al. Further delineation of the phenotype resulting from BRAF or MEK1 germline mutations helps differentiate cardio-facio-cutaneous syndrome from Costello syndrome. Am J Med Genet A. 2007;143A(13):1472-1480. doi:10.1002/ajmg.a.31815

21. De Schrijver L, Topsakal V, Wojciechowski M, Van de Heyning P, Boudewyns A. Prevalence and etiology of sensorineural hearing loss in children with down syndrome: a Cross-Sectional Study. Int J Pediatr Otorhinolaryngol. 2019;116:168-172. doi:10.1016/j. ijporl.2018.10.048

22. Shankar SP, Young T, Burner E, et al. Visual and auditory features in cardio-facio-cutaneous syndrome. J Investig Med. 2009;7:115.

23. Bonnard Å, Bark R, Hederstierna C. Clinical update on sensorineural hearing loss in Turner syndrome and the X-chromosome. Am J Med Genet C Semin Med Genet. 2019;181(1):18-24. doi:10.1002/ajmg. c. 31673

24. Mey K, Muhamad AA, Tranebjaerg L, et al. Association of SLC26A4 mutations, morphology, and hearing in Pendred syndrome and NSEVA. Laryngoscope. 2019;129(11):2574-2579. doi:10.1002/ lary. 27319

25. Kreicher KL, Weir FW, Nguyen SA, Meyer TA. Characteristics and progression of hearing loss in children with down syndrome. J Pediatr. 2018;193:27-33.e2. doi:10.1016/j.jpeds.2017.09.053

26. Miguel HC, Carneiro CG, Tabith A Jr, Zechi-Ceide RM, Genaro KF. Laryngeal malformation in Richieri-Costa Pereira syndrome: new findings. Am J Med Genet A. 2012;158A(8):1967-1970. doi:10.1002/ajmg.a.35421

27. Paolantonio EG, Ludovici N, Saccomanno S, La Torre G, Grippaudo C. Association between oral habits, mouth breathing and malocclusion in Italian preschoolers. Eur J Paediatr Dent. 2019;20 (3):204-208.

28. Harari D, Redlich M, Miri S, Hamud T, Gross M. The effect of mouth breathing versus nasal breathing on dentofacial and craniofacial development in orthodontic patients. Laryngoscope. 2010;120 (10):2089-2093. doi:10.1002/lary.20991

29. Saitoh I, Inada E, Kaihara Y, et al. An exploratory study of the factors related to mouth breathing syndrome in primary school children. Arch Oral Biol. 2018;92:57-61. doi:10.1016/j. archoralbio.2018.03.012

30. Bonilha HS, O'Shields M, Gerlach TT, Deliyski DD. Arytenoid adduction asymmetries in persons with and without voice disorders. Logoped Phoniatr Vocol. 2009;34(3):128-134. doi:10.1080/ 14015430903150210

31. Adviento B, Corbin IL, Widjaja F, et al. Autism traits in the RASopathies. J Med Genet. 2014;51(1):10-20. doi:10.1136/jmedgenet-2013-101951

32. Garg S, Brooks A, Burns A, et al. Autism spectrum disorder and other neurobehavioural comorbidities in rare disorders of the Ras/ MAPK Pathway. Dev Med Child Neurol. 2017;59(5):544-549. doi:10.1111/dmen.13394

Counselling and ethical issues; Animal models; Pharmacogenetics Prenatal diagnosis; Dysmorphology. The manuscript management system is completely online and includes a very quick and fair peerreview system, which is all easy to use. Visit http://www.dovepress. com/testimonials.php to read real quotes from published authors. 